\title{
Memory of self-performed tasks: Self-performing during recognition
}

\author{
JOHANNES ENGELKAMP, HUBERT D. ZIMMER, GILBERT MOHR, and ODMAR SELLEN \\ University of the Saarland, Saarbrilcken, Germany
}

\begin{abstract}
Two experiments focused on whether performing actions described by to-be-remembered phrases during recognition enhances recognition compared with results of a standard verbal recognition test. The enhancement was predicted when the actions described by the phrases had been performed during study, but not when the phrases were verbally encoded by simply listening to and memorizing the material. Both experiments showed that enactment prior to recognition improved memory performance, but only when subjects had encoded by enactment. Experiment 1 also demonstrated that this test-procedure effect was independent of a bizarreness effect, which was observed only with the verbal encoding task. Experiment 2 showed that the effect of enactment during recognition was reduced when subjects used different hands for performing the actions during study and recognition. The findings support the assumption that some kind of motor memory record underlies the enactment effect that occurs when actions are performed during recognition.
\end{abstract}

Action phrases such as "cut the bread" are retained better when subjects encode the phrases by selfperforming the denoted actions than when they learn the phrases under standard verbal learning instructions-that is, by performing verbal tasks (VTs). This effect of selfperformed tasks (SPTs) has been extensively replicated for recall as well as for recognition (for reviews see Cohen, 1989b; Engelkamp, 1991; Engelkamp \& Zimmer, 1985). Different explanations of this effect have been proposed (e.g., Bäckman, Nilsson, \& Chalom, 1986; Cohen, 1985; Zimmer \& Engelkamp, 1989) and are still under debate. They have brought about some clarification, however, insofar as some aspects have been shown to be definitely irrelevant for the SPT effect. The SPT effect is, for instance, independent of whether imaginary or real objects are used in performing the tasks (Engelkamp \& Zimmer, 1983, 1992). Moreover, enactment of the denoted actions seems to be the decisive factor because the SPT effect can be observed even if the subjects close their eyes while performing the action; thus, seeing the task performed by oneself is not necessary for production of the SPT effect (Engelkamp, Zimmer, \& Biegelmann, in press). Engelkamp (1991; Zimmer \& Engelkamp, 1989) proposes, therefore, that the motor information provided by enactment is a critical component of the SPT effect. This hypothesis is supported by selective interference experiments in which memory after SPTs was selectively impaired by secondary SPTs (Saltz \& Donnenwerth-

This research was supported by Grant EN 124/8 from the German Science Foundation (DFG) to J.E. and H.Z. Correspondence concerning this article should be addressed to J. Engelkamp or H. D. Zimmer, Department of Psychology, University of the Saarland, P.O. Box 1150, D-66041 Saarbrücken, Germany (e-mail address: engelkamp@rz.uni-sb.de).

-Accepted by previous editor, Margaret Jean Intons-Peterson
Nolan, 1981; Zimmer \& Engelkamp, 1985; cf., however, Cohen, 1989a, who was not able to observe a motor interference effect).

In this research, we asked whether motor information encoded when action phrases are enacted can be exploited when the phrases are enacted again during recognition. In other words, we wanted to demonstrate that motor information that is tied to enactment can be used under specific circumstances in explicit recognition memorynamely, when subjects enact again during recognition. Thus, we expected that the usual SPT effect in recognition would be enhanced when subjects also performed the actions during recognition.

It is surprising that most of the research cited above tested the SPT effect with verbal recall and, more recently, with verbal recognition (Engelkamp et al., in press; Knopf, 1991; Koriat, Ben-Zur, \& Druch, 1991; Mohr, Engelkamp, \& Zimmer, 1989). According to the principles of transfer-appropriate processing (e.g., Jacoby, 1991; Roediger, 1990; Roediger \& Blaxton, 1987; Roediger, Weldon, \& Challis, 1989) and encoding specificity (Tulving \& Thomson, 1973), the advantage of SPT instructions should have been underestimated in previous studies because enactment was not reinstated during testing. These principles suggest that performance on a recognition test will improve if some of the original conditions of study occur at the time of test. This prediction follows directly from the principle that "performance on memory tasks benefits to the extent that cognitive operations at test recapitulate (or overlap) those engaged during initial learning' (Roediger, 1990). Hence, after SPT learning, recognition should be enhanced if subjects are required to enact the phrases prior to this recognition decision. However, enacting during testing should have no positive effect on recognition after VT learning because motor information provided by enactment in this case has 
not been encoded. Thus, we predicted an interaction between type of encoding and type of testing.

Besides type of encoding and type of testing, we included bizarreness as a further factor because it produced an interaction with type of encoding in several studies (Engelkamp et al., in press; Knopf, 1991; Mohr et al., 1989). Bizarre phrases such as "comb the toothbrush" were better recognized than ordinary phrases such as "open the book" after verbal tasks, but there was no difference between these types of phrases after SPTs. Bizarre phrases were constructed by forming unusual combinations of common object nouns and action verbs. Engelkamp et al. (in press) explained the different effect of bizarreness on recognition after VTs and SPTs by assuming that recognition is based on verbal episodes after VTs and on action episodes after SPTs. They assumed furthermore that bizarreness is a feature of the verbal episode and not of the action episode. Although objects of bizarre phrases are seldom used for the particular action, the action pattern itself is not bizarre. They could support these assumptions by showing that the interaction between bizarreness and type of encoding disappeared when subjects were forced to retrieve the verbal episode in the memory testthat is when object words were used to cue the action verbs. Under these conditions there was a bizarreness effect even after SPT learning.

If bizarreness is a feature of the verbal episode and is not used after SPT learning, bizarreness also should be independent of type of testing. We wanted to replicate the reported interaction and to extend it to type of testing. Moreover, combining type of encoding with bizarreness and with type of testing permits an assessment of the following dissociation. After VT learning, the manipulation of the test procedure should be ineffective and performance should be lower for ordinary phrases than for bizarre ones. After SPT learning, on the other hand, recognition memory should be better after SPT testing than after VT testing, and there should be neither an effect of bizarreness nor an interaction of bizarreness and type of testing. Such a pattern would support the assumption that the effect of SPT testing after SPT learning reflects different information from that given by bizarreness.

\section{EXPERIMENT 1}

\section{Method}

Subjects. Thirty-two subjects participated in the experiment. They were all students at the University of the Saarland, and were paid for their participation.

Materials and Procedure. The subjects studied 80 action phrases individually. Half of the phrases, such as "open the book," were ordinary, and half, such as "plant the hammer," were bizarre. All phrases were constructed from a common pool of concrete nouns and action verbs. For ordinary phrases, verb-object combinations that occur commonly were selected. Bizarre phrases, on the other hand, were formed by selecting combinations of verbs and objects that were unusual and new for the subjects. Ordinary and bizarre phrases were ordered randomly and were read aloud to all 32 subjects in fixed order at a rate of $6 \mathrm{sec}$ per item. Sixteen subjects learned the list by performing the actions with imaginary objects
(SPT), and 16 did so by only listening to the phrases and trying to memorize them (VT).

For the recognition test, eight test lists were constructed, each consisting of 90 items. Of the 40 items in each test list that were "old," half were ordinary and half were bizarre. The remaining 50 items were distractors. Among these, 10 were completely new action phrases, while 40 were constructed from old items (half ordinary and half bizarre), as follows: in 20 , the object of the original phrase was replaced; in the remaining 20 , the verb of an old item was replaced. The eight test lists resulted from counterbalancing the items of the list to be learned and the different distractor types.

Each subject was tested with two different test lists in the recognition test. The first recognition test was always verbal, while the second was always an SPT recognition test. The two lists were counterbalanced in such a way that half of the subjects received those items in the verbal recognition test that the remaining subjects received in the SPT recognition test. Thus, all items were tested equally often under verbal and motor recognition and no item was tested twice with the same subject. The order of testing-type was fixed, with VT testing coming first in order to avoid carry-over effects from SPT testing to VT testing. Such carry-over effects could have disguised the effect of SPT testing after SPT learning. Furthermore, any carry-over effects from the fixed order should benefit the VT learning group, an influence that works against our hypothesis.

Prior to the recognition test, the subjects were informed about the kind of distractors used and instructed on how they had to make their recognition decision. Prior to the verbal recognition task, subjects were instructed that they would be given a first recognition list in the following way: They would see a series of single action phrases on a computer screen at a rate of $3 \mathrm{sec} /$ item. For each item they should decide whether it was old or new by pressing one of two buttons. After they had passed this verbal recognition test, they were told that they would be given a second test and that this time they should perform the action with each item before making the recognition decision. They were given three seconds more per item to perform the actions in this test condition.

Design. A $2 \times(2 \times 2)$ design was used with the following factors: type of encoding; type of testing; and type of material. Only the first factor was measured between subjects. Neither the different test lists that served as controls nor the different types of distractors were included as factors in the statistical analyses.

\section{Results}

We conducted two analyses of recognition performance. The first analysis was based on the PR scores (i.e., the rate of hits minus the rate of false alarms), after Snodgrass and Corvin (1988), and the second on the relative frequencies of hits. The results in terms of the PR scores, hits, and false alarms are shown in Table 1.

The following effects were significant in the analysis of PR scores. Recognition performance was better after SPT learning $(.88)$ than after VT learning $(.71)[F(1,30)=$ $\left.24.38, M S_{\mathrm{e}}=.0388, p<.001\right]$. Recognition performance was also better after SPT testing (.80) than after VT testing $(.78)\left[F(1,30)=4.19, M S_{\mathrm{e}}=.016, p<.05\right]$, as it was, too, for bizarre phrases (.82) compared with ordinary phrases $(.77)\left[F(1,30)=5.94, M S_{\mathrm{e}}=.0126\right.$, $p<.05]$. Furthermore, there was an interaction between type of encoding and type of testing $\left[F(1,30)=5.64, M S_{e}\right.$ $=.0116, p<.05]$, showing that type of testing only affected recognition performance after SPT learning $[F(1,30)=9.79, p<.005]$, and not after VT learning $(F<1$; see Figure 1$)$. There was also an interaction be- 
Table 1

Hit Rates, False-Alarm Rates, and PR Scores as a Function of Type of Encoding, Type of Testing, and Type of Material

\begin{tabular}{|c|c|c|c|c|}
\hline \multirow[b]{3}{*}{ Type of Encoding } & \multicolumn{4}{|c|}{ Type of Testing } \\
\hline & \multicolumn{2}{|c|}{ Verbal Task } & \multicolumn{2}{|c|}{$\begin{array}{c}\text { Subject-Performed } \\
\text { Task }\end{array}$} \\
\hline & $\begin{array}{l}\text { Ordinary } \\
\text { Material }\end{array}$ & $\begin{array}{c}\text { Bizarre } \\
\text { Material } \\
\end{array}$ & $\begin{array}{l}\text { Ordinary } \\
\text { Material }\end{array}$ & $\begin{array}{c}\text { Bizarre } \\
\text { Material } \\
\end{array}$ \\
\hline \multicolumn{5}{|c|}{ Hits } \\
\hline Verbal Task & .73 & .85 & .71 & .85 \\
\hline Subject-performed task & .92 & .89 & .96 & .95 \\
\hline \multicolumn{5}{|c|}{ False Alarms } \\
\hline Verbal task & .09 & .06 & .07 & .08 \\
\hline Subject-performed task & .05 & .08 & .02 & .04 \\
\hline \multicolumn{5}{|c|}{ PR Scores } \\
\hline $\begin{array}{l}\text { Verbal task } \\
\text { Subject-performed task }\end{array}$ & $\begin{array}{l}.64 \\
.87\end{array}$ & $\begin{array}{l}.79 \\
.81\end{array}$ & $\begin{array}{l}.64 \\
.94\end{array}$ & $\begin{array}{l}.78 \\
.91\end{array}$ \\
\hline
\end{tabular}

tween type of encoding and type of material $[F(1,30)=$ 21.51, $\left.M S_{\mathrm{e}}=.0126, p<.001\right]$; and bizarreness improved recognition memory after VT learning $[F(1,30)=$ $25.03, p<.001]$, but not after SPT learning $[F(1,30)$ $=2.42, p>.10$; see Figure 2].

The effects in the analysis of hits corresponded to the effects in the PR analysis. The following effects were significant: type of encoding $\left[F(1,30)=37.52, M S_{\mathrm{e}}=\right.$ $.0180, p<.01]$; type of material $\left[F(1,30)=7.11, M S_{\mathrm{e}}\right.$ $=.0150, p<.05]$; the interaction between type of encoding and type of testing $\left[F(1,30)=5.23, M S_{\mathrm{e}}=.0054\right.$, $p<.05]$; and the interaction between type of encoding and type of material $\left[F(1,30)=10.98, M S_{\mathrm{e}}=.0150\right.$, $p<.01]$. Performing the actions during test improved hit rates after learning by enactment $[F(1,30)=6.96, p<$ $.01]$, but not after verbal learning $(F<1)$. On the contrary, bizarreness influenced recognition in the VT condition $[F(1,30)=17.88, p<.001]$, but not in the SPT condition $(F<1)$.

False alarms were rare events in this study. We therefore analyzed only whether the false-alarm rate depended on type of testing - and this only under motor encoding. Motor encoding during testing did reduce the rate of false alarms in this case $[t(15)=2.35, p<.04]$. After motor learning, there were fewer false alarms if subjects enacted during testing (.03) than if they did not (.07). The corresponding values after verbal learning were .08 for motor testing and .07 for verbal testing.

\section{Discussion}

The analyses yielded three important results: (a) compared with VT testing, SPT testing enhances recognition (PR scores) after SPT learning (.93 vs .84), but not after VT learning (.71 vs .72); (b) bizarreness improves recognition after VT learning (.64 vs .79) but not after SPT learning (.91 vs .86); and (c) the bizarreness effect after VT learning is independent of type of testing.

The first result-that enactment during testing increases recognition after SPT learning - reflects more processing overlap when subjects enact during learning and testing than when they enact only during learning. Moreover, the fact that verbal learning does not benefit from enacting during testing demonstrates that the information provided by enacting during testing is not available after verbal learning. Thus, there is information encoded by SPTs that can be tapped by testing with SPTs that is not encoded by VTs. We suggest that it is motor information that enhances recognition after SPT encoding.

This interpretation is supported by the two other results-namely, that bizarreness influences recognition after VT learning but not after SPT learning, and that this effect is independent of whether testing is verbal or motor. As argued above, if recognition after SPT learning relies on retrieving and assessing action episodes, and if bizarreness is a feature of the verbal episode, then bizarreness should not influence recognition memory after SPT learning under either verbal or motor testing. Only recognition after VT learning should depend on bizarreness.

Thus, there is a dissociation of the effects of bizarreness and type of testing. Verbal learning is influenced by bizarreness but not by type of testing, whereas SPT learn-

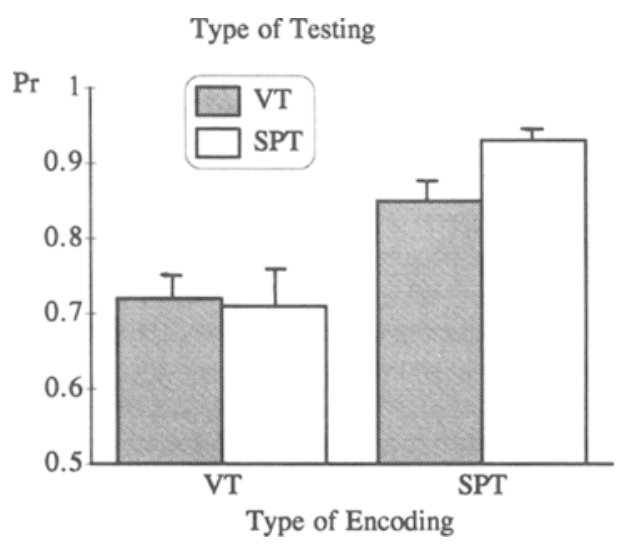

Figure 1. Mean PR scores as a function of type of encoding and type of testing. Error bars show standard errors of the mean.

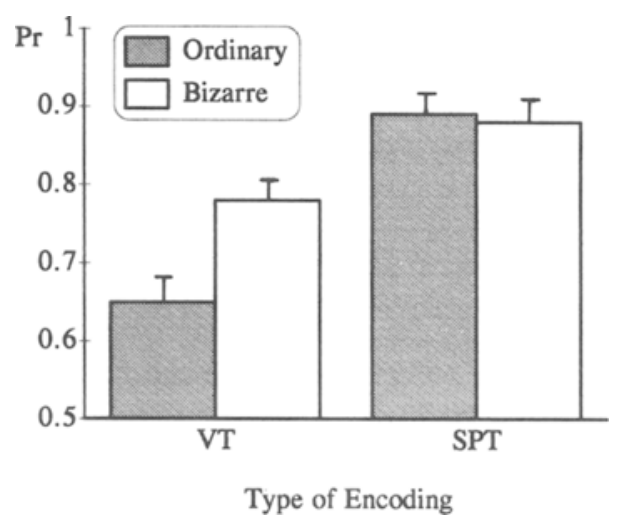

Figure 2. Mean PR scores as a function of type of encoding and type of material. Error bars show standard errors of the mean. 
ing is influenced by type of testing but not by bizarreness. This suggests that the motor nature of SPTs is retained and can be accessed by appropriate test procedures.

\section{EXPERIMENT 2}

Experiment 2 was planned to give further support to the interpretation that the effect of enactment during testing is mediated by motor information. To do so, we looked for possibilities to influence the effect of SPT testing by manipulating the similarity between the movement during encoding and testing. Transfer-appropriate motor processing should be high if the same motor movement for an action is executed during learning and testing, and it should be lower when there is some change in motor performance with an action. We manipulated the similarity of motor information in study and test by having the actions performed either by the same hand or by different hands. Using the same hand to perform the action during study and test should establish more overlap of motor information than using a different hand for study than for test. Transfer-appropriate processing, and thus recognition, should be better if the same hands were used in the study and test phase than if different hands were used.

In addition to testing this hypothesis, Experiment 2 was planned to replicate from Experiment 1 the differential effect of enactment during testing after VT and SPT learning.

\section{Method}

Subjects. Forty-eight different students of the University of the Saarland took part in the experiment; they were paid for their participation.

Materials, Design, and Procedure. The learning and distractor items were 150 action verbs. Of these verbs, 100 denoted actions that are usually performed with only one hand, such as "knock," "mark," "point," "hammer," and the other 50 denoted actions that are usually performed with two hands, such as "peel," "tear up," and "knot." Of the 100 "one-hand" verbs, 60 were randomly selected and served as learning items, while the other 40 served as distractors. Of the 50 "two-hand" verbs, 30 were randomly selected as learning items, and the remaining 20 served as distractors. The 60 one-hand and the 30 two-hand "learning" verbs together formed the learning list.

The 48 subjects were divided into two groups of 24 subjects each. One group learned the items in a verbal task and the other learned the items in a subject-performed task. The SPT group listened to the 90 verbs and performed all two-hand and one-hand items, half of the one-hand actions with their right hand and half with their left hand; the one-hand items that were performed by half of the subjects with their right hand were performed by the other half with their left hand, and vice versa. During the study phase, the subjects of the SPT group were acoustically requested by the words "right," "left," and "both"' to perform the action correspondingly with the right hand, the left hand, or with both hands.

The VT group listened to the 90 items without performing the actions, but they simply tried to memorize them. The presentation rate was $6 \mathrm{sec} /$ item for both groups.

The presentation of the 90 verbs was followed by a recognition test. Whereas the learning list was presented acoustically using a tape recorder, the recognition list of 150 items was presented visually on a computer screen. Part of the items had to be performed be- fore the subjects decided whether a verb was old or new. Enactment was again with the right hand, the left hand, or with both hands.

Presentation of the items during testing was the same for the subjects of the VT and the SPT groups. All items were first to be read aloud and then-corresponding to an exclamation mark on the right side of the item, on the left side, or on both sides-it was communicated to the subjects that they had to perform the action with their right hand, their left hand, or with both hands. Items that should not be performed but only read aloud were marked by a hyphen on both sides of the item. Thereafter, subjects had to make their old $/$ new decision. The items were visible for $7 \mathrm{sec}$.

All one-hand items (the one-hand distractors included) were tested under enactment only: half of these items were performed with the right hand and half with the left hand. Note that no subject of the VT group had performed any item during learning. For the subjects of the SPT group who had performed all old items during learning, enactment during testing was organized in such a way that half of the learned items were tested by using the same hand as during study and half by using the other hand.

To guarantee that each of the one-hand items to be learned was performed by half of the subjects of the SPT group with their right hand and by the other half with their left hand, two different learning lists were formed. Furthermore, to ensure that each one-hand item was also tested with both right- and left-hand enactment for each learning list, two recognition lists were formed. Altogether, this resulted in four recognition lists.

This arrangement in one list of one-hand and two-hand items that were learned and tested either in VTs or in SPTs served to realize the following designs.

First, since the both-hand items were learned either in VTs or in SPTs and tested in VTs or in SPTs, we replicated the two-factorial split-plot design that was part of Experiment 1 . It contained the factors type of encoding (VT/SPT) and type of testing (VT/SPT), with the first factor as a between-subjects variable. During recognition, subjects of both learning groups performed half of the two-hand items and only read the other half. Over subjects, the assignment of items to testing conditions was counterbalanced. Unlike in Experiment 1, VT testing and SPT testing were not blocked in Experiment 2 . The mixed order of testing conditions in this experiment allows us to rule out the possibility that the findings of Experiment 1 were due to test order of VT and SPT.

Second, a $2 \times 2$ within-subjects design was realized because the subjects who learned the one-hand items in SPTs, and who were tested for them in SPTs, were tested for half of them with the same (ipsilateral) hand as used during study, and for half with the other (contralateral) hand than used during study. The factors were congruence of hands (ipsilateral/contralateral) and hand of testing (left/right).

Finally, because the VT subjects also learned the one-hand items and these items were tested under enactment, half being performed with the right and half with the left, these subjects constituted a control condition for the one-hand items.

\section{Results}

Analyses of two-hand items. Three analyses were conducted, one of PR scores, one of hit rates, and one of false-alarm rates. All analyses of variance (ANOVAs) used type of encoding as a between-subjects factor and type of testing as a within-subjects factor. Because four subjects had already yielded hit rates of 1 under VT testing and left no space for further enhancement, they were excluded from the analyses.

The analysis of PR scores of the remaining 44 subjects revealed that SPT learning (.74) was better than VT learn- 
ing (.42) $\left[F(1,42)=25.87, M S_{\mathrm{e}}=.0867, p<.001\right]$ and that type of encoding interacted with type of testing $\left[F(1,42)=4.20, M S_{\mathrm{e}}=.0203, p<.05\right]$. The interaction is shown in Table 2.

The effects in the analysis of hits corresponded to the effects in the PR analysis. The following effects were significant: There were more hits after SPT learning (.88) than after VT learning (.69) $\left[F(1,42)=38.19, M S_{\mathrm{e}}=\right.$ $.0199, p<.001]$; there was a significant effect of type of testing $\left[F(1,42)=10.62, M S_{\mathrm{e}}=.0085, p<.005\right]$, showing that there were more hits after SPT testing (.82) than after VT testing (.75); and there was again a significant interaction between both factors $[F(1,42)=8.04$, $\left.M S_{\mathrm{e}}=.0085, p<.01\right]$.

Both analyses showed that with SPT learning, performance was better under SPT testing than under VT testing $[F(1,42)=2.77, p<.10$ for $\mathrm{PR} ; F(1,42)=17.03$, $p<.001$ for hits], whereas after VT learning, type of testing did not influence recognition $(F<1.5, p>.20)$. Thus, after learning by enactment, recognition was enhanced if subjects enacted again during test, but after verbal learning the type of testing was unimportant for recognition performance.

Finally, the false-alarm rates were submitted to the same analysis. Here, type of encoding was significant $[F(1,42)=$ $\left.7.82, M S_{\mathrm{e}}=.0502, p<.01\right]$. There were more false alarms after VT learning (.27) than after SPT learning (.13), and there was a marginally significant effect of type of testing $\left[F(1,42)=3.58, M S_{e}=.0163, p<.07\right]$. There were more false alarms after SPT testing (.23) than after VT testing (.17), but the interaction between the two factors was insignificant $(F<1)$.

Analyses of one-hand items. The ANOVA of the onehand items that were learned and tested under enactment with the factors ipsilateral versus contralateral testing and right versus left test-hand was only conducted for the hit rates, because false alarms could not be attributed to the different experimental conditions in this design. Because there were 6 subjects of 24 who already had hit rates of 1 under contralateral testing, the analysis was conducted over the remaining 18 subjects. The ANOVA was carried out for a two-factorial within-subjects design with the factors test-hand and congruency of the hand used at

Table 2

Hit Rates, False-Alarm Rates, and PR Scores as a Function of Type of Encoding and Type of Testing for "Two-Hand" Items

\begin{tabular}{lcc}
\hline & \multicolumn{2}{c}{ Type of Testing } \\
\cline { 2 - 3 } Type of Encoding & $\begin{array}{c}\text { Verbal } \\
\text { Task }\end{array}$ & $\begin{array}{c}\text { Subject-Performed } \\
\text { Task }\end{array}$ \\
\hline & Hits & \\
Verbal task & .69 & .69 \\
Subject-performed task & .82 & .94 \\
& False Alarms & \\
Verbal task & .24 & .30 \\
Subject-performed task & .11 & .16 \\
& PR Scores & \\
Verbal task & .45 & .40 \\
Subject-performed task & .71 & .78 \\
\hline
\end{tabular}

study and at test. The analysis yielded only one significant effect: There were more hits under ipsilateral $(.87)$ than under contralateral testing $(.80)[F(1,17)=7.50$, $\left.M S_{\mathrm{e}}=.0119, p<.05\right]$. Whether testing was with the right or left hand had no effect $(F<1)$, and there was no hint of an interaction $(F<1)$. The hit rates are given in Table 3.

Finally, we tested the hit rates of the one-hand items of the verbal-learning group, depending on whether they were tested with the left or right hand. This effect was not significant $\left[F(1,23)=1.35, M S_{\mathrm{e}}=.0083, p>.25\right.$ (right hand $=.69$, left hand $=.66$ )]. The same effect was observed for the false alarms of this group $[F(1,23)=$ $1.24, M S_{\mathrm{e}}=.1003, p>.25$ (right hand $=.29$, left hand $=.32$ )]. Additionally, in the VT group hit rates and false alarms for these performed one-hand items were as high as those values for the performed two-hand items and for the verbally tested two-hand items $(F<1)$. The corresponding hit values were .69 for the right hand, .66 for the left hand, .69 for the items performed at test, and .69 for the verbally tested two-hand items.

\section{Discussion}

The results of Experiment 2 demonstrated again that self-performing a task produces information that is not produced under verbal learning and that a repetition of action during recognition facilitates performance. We postulate that this information is tightly bound to the execution of overt motor behavior and therefore to motor and not verbal information.

To test this hypothesis more strongly, we varied only the motor component and kept the verbal component constant. We did so by changing the hand with which an action was performed from study to test. This change of the performing hand should have reduced recognition performance relative to using the same hand at study and test if information of the performing hand is decisive. This was, indeed, what we observed: changing the performing hand from learning to testing decreased recognition relative to using the same hand again. This result shows that the information that is made available by SPTs does not only depend on the fact that an action is performed, but is also dependent on the particular hand with which an action is performed.

\section{GENERAL DISCUSSION}

Both experiments were designed to test the assumption that the information provided by enactment is at least partly motor information and that this information is used in recognition memory when enactment takes place also during testing. Evidence should favor this assumption if enactment during testing increased performance in the recognition test compared with verbal testing after SPT learning and did not increase recognition performance after VT learning. The results of both experiments corroborated this hypothesis.

Experiment 1 served to support this hypothesis further by demonstrating that a bizarreness characteristic of verbal 
Table 3

Hit Rates of "One-Hand" Items as a Function of Congruency of the Hand Used at Study and Test and of the Hand Used at Test

\begin{tabular}{ccc}
\hline \multirow{2}{*}{$\begin{array}{c}\text { Congruency of Hand } \\
\text { at Study and Test }\end{array}$} & \multicolumn{2}{c}{ Test-Hand } \\
\cline { 2 - 3 } Left & Right \\
\hline Ipsilateral & .88 & .87 \\
Contralateral & .80 & .80 \\
\hline
\end{tabular}

episodes, but not of enactment, does not influence recognition after SPT learning and does not modify the enhancing effect of SPT testing after SPT learning. Bizarreness did, however, enhance recognition, while it was independent of type of testing after VT learning. This dissociation demonstrates that qualitatively different mechanisms underlie the two effects. Whatever makes bizarre items more distinctive, this kind of information is not tapped by performing the actions at test. Moreover, the information released by performing items at test is only available for those items that were enacted during study.

By a further variation, Experiment 2 served also to support the basic hypothesis that SPT learning provides motor information and that this information is used in recognition memory if motor testing is used. In this experiment, we considered all encoding processes of the SPT subjects during study and test to be equal, except for the hand used to perform the action. If one agrees that whether one performs an action (for instance, tapping) with the right or left hand, the conceptual information of the verb processed does not change, then there should be no effect on recognition dependent on whether one uses the same or a different hand to perform an action at study and test unless some information other than conceptual information determines recognition. The results showed that there was a hand-congruency effect. Therefore, we attribute this effect to the different motor processes involved in performing actions with different hands.

We thus conclude that at least part of SPT encoding is motor information and that this information is used if SPTs are used again to test recognition. Although this study does not clarify what causes the usual SPT effect, it suggests that enactment provides motor information and that this information is used under appropriate testing conditions.

\section{REFERENCES}

Bäckman, L., Nilsson, L.-G., \& Chalom, D. (1986). New evidence on the nature of the encoding of action events. Memory \& Cognition, 14, 339-346.
ConeN, R. L. (1985). On the generality of the laws of memory. In L.G. Nilsson \& T. Archer (Eds.), Animal learning and human memory (pp. 247-277). Hillsdale, NJ: Erlbaum.

CoHEN, R. L. (1989a). The effects of interference tasks on recency in the free recall of action events. Psychological Research, 51, 176-180.

CoHen, R. L. (1989b). Memory for action events: The power of enactment. Educational Psychology Review, 1, 57-80.

Engelkamp, J. (1991). Das menschliche Gedächtnis (2nd ed.). Göttingen: Hogrefe

ENGELKAMP, J., \& Zimmer, H. D. (1983). Zum Einfluß von Wahrnehmen und Tun auf das Behalten von Verb-Objekt-Phrasen. Sprache \& Kognition, 2, 117-127.

ENGelKAMP, J., \& Zimmer, H. D. (1985). Motor programs and their relation to semantic memory. German Journal of Psychology, 9, 239-254.

ENGELKAMP, J., \& ZimMER, H. D. (1992). The role of objects for memory in subject-performed tasks and in experimenter-performed tasks. Unpublished manuscript, University of the Saarland, Saarbrücken.

EngelKamp, J., Zimmer, H. D., \& BiegelmanN, U. E. (in press). Bizarreness effects in verbal tasks and subject-performed tasks. European Journal of Cognitive Psychology.

JACOBY, L. L. (1991). A process dissociation framework: Separating automatic and intentional uses of memory. Joumal of Memory \& Language, 30, 513-541.

KNOPF, M. (1991). Having shaved a kiwi fruit: Memory of unfamiliar subject-performed actions. Psychological Research, 53, 203-211.

Koriat, A., Ben-ZUR, H., \& Druch, A. (1991). The contextualization of input and output events in memory. Psychological Research, 53, 260-270.

Mohr, G., Engelkamp, J., \& Zimmer, H. D. (1989). Recall and recognition of self-performed acts. Psychological Research, 51, 181-187.

RoEDiGer, H. L., III (1990). Implicit memory: Retention without remembering. American Psychologist, 45, 1043-1056.

RoEdiger, H. L., III, \& Blaxton, T. A. (1987). Effects of varying modality, surface features, and retention interval on priming in wordfragment completion. Memory \& Cognition, 15, 379-388.

Roediger, H. L., III, Weldon, M. S., \& Challis, B. H. (1989). Explaining dissociations between implicit and explicit measures of retention: A processing account. In H. L. Roediger III \& F. I. M. Craik (Eds.), Varieties of memory and consciousness: Essays in honour of Endel Tulving (pp. 3-14). Hillsdale, NJ: Erlbaum.

Saltz, E., \& Donnenwerth-Nolan, S. (1981). Does motoric imagery facilitate memory for sentences? A selective interference test. Journal of Verbal Learning \& Verbal Behavior, 20, 322-332.

SNOdgrass, J. G., \& Corvin, J. (1988). Pragmatics of measuring recognition memory: Applications to dementia and amnesics. Journal of Experimental Psychology: General, 117, 4-50.

Tulving, E., \& Thomson, D. M. (1973). Encoding specificity and retrieval processes in episodic memory. Psychological Review, 80, 352-373.

Zimmer, H. D., \& EngelKamp, J. (1985). An attempt to distinguish between kinematic and motor memory components. Acta Psychologica, 58, 81-106.

Zimmer, H. D., \& ENGElKamp, J. (1989). One, two or three memories? Some comments and new findings. Acta Psychologica, 70, 293-304.

(Manuscript received November 6, 1992; revision accepted for publication May 14, 1992.) 